\section{Public Health Genomics}

Public Health Genomics 2010;13:431-439

DOI: $\underline{10.1159 / 000317099}$
Received: November 25, 2009

Accepted after revision: June 16, 2010 Published online: September 9, 2010

\title{
Preferences regarding Genetic Research Results: Comparing Veterans and Nonveterans Responses
}

\author{
N. Arar J.Seo S. Lee H.E. Abboud L.A. Copeland P. Noel M. Parchman \\ Division of Nephrology, Department of Medicine, University of Texas Health Science Center at San Antonio, \\ Audie L. Murphy Memorial Veterans Hospital, San Antonio, Tex., USA
}

\section{Key Words}

Common complex diseases • Ethics • Genetic family

studies $\cdot$ Research results

\begin{abstract}
Objective: Communicating genetic research results to participants presents ethical challenges. Our objectives were to examine participants' preferences in receiving future genetic research results and to compare preferences reported by veteran and nonveterans participants. Methods: Secondary analysis was performed on data collected in 2000-2004 from 1,575 consent forms signed by Mexican-American participants enrolled in 2 genetic family studies (GFS) in San Antonio: The Family Investigation of Nephropathy and Diabetes (FIND) and the Extended FIND (EFIND). The consent forms for these studies contained multiple-choice questions to examine participants' preferences about receiving their (1) clinical lab results and (2) future genetic research results. The FIND and EFIND databases had information on subjects' demographic characteristics and some selected clinical variables. We identified veterans using the Veterans Health Administration's (VHA's) centralized data repository. We compared veterans' and nonveterans' preferences using Student's $t$ test for continuous variables and $\chi^{2}$ test for discrete variables. A logistic regression analyzed subjects' preference for receiving their research results, controlling for other socio-demographic and clinical variables. Results: The sample included 275 (18\%) veterans and 1,247 (82\%) nonveterans.
\end{abstract}

Our results indicated a strong desire among the majority of participants 1,445 (95\%) in getting their clinical lab research results. Likewise, $93 \%$ expressed interest in being informed about their future genetic results. There was no significant difference in veterans' and nonveterans' preference to disclosure of the research results ( $\chi^{2}$ test; $\left.p>0.05\right)$. Regression analysis showed no significant relationship $(p=0.449)$ between the outcome (receiving research results) and veterans' responses after controlling for demographics and educational levels. Conclusion: Participants believed they would prefer receiving their genetic research results. Veterans are similar to nonveterans in their preferences. Offering genetic research results to participants should be based on well defined and structured plans to enhance interpretation of genetic data.

Copyright $\odot 2010$ S. Karger AG, Basel

\section{Introduction}

In light of recent advances in genomic research, there has been an increased interest in and proliferation of genome-wide association studies (GWAS). In GWAS, thousands of genes from large numbers of people are linked to different types of phenotypes in order to identify polymorphisms that influence susceptibility to several common chronic diseases [1]. Knowledge about genetic susceptibilities has the potential to transform the practice of medicine by enhancing diagnostic and treatment ap-

\section{KARGER}

(C) 2010 S. Karger AG, Basel

Fax +41613061234 E-Mail karger@karger.ch www.karger.com
Accessible online at: www.karger.com/phg
Nedal Arar, PhD

Department of Medicine/Nephrology, University of Texas Health Science Center a

San Antonio, South Texas Health Care System

7703 Floyd Curl Drive, San Antonio, TX 78229-3900 (USA)

Tel. +1 210567 0075, Fax +1 210567 4712, E-Mail ararn@ uthscsa.edu 
proaches for common chronic diseases [2]. Although the prospective advantages of GWAS are promising, there are several challenges involved in integrating findings from GWAS into clinical practice $[3,4]$. One important challenge is the ethical considerations associated with communicating genetic research results with participants.

Several ethical principles guide biomedical research and practices, including respect for persons, beneficence, reciprocity, and justice [5]. These principles provide a justification for returning individual genetic research results to participants, most notably the principle of respect for persons. According to some proponents of this practice, this principle suggests that researchers should respect the desires of participants and not treat them as a means to an end [6-8]; therefore, respect for persons proposes that researchers should ideally return individual results to research participants if it is in line with the participants' desires. Some authors have further argued that the return of research results requested by participants may in turn 'increase participants' willingness to enroll, thereby facilitating future participations,' offering another advantage of returning results $[8,9]$. However, several issues have been raised as barriers to implementing this practice. One such concern is due to the uncertain nature of genetic research findings, as they may not necessarily predict the development and severity of a condition [10]. Additionally, many GWAS are hypothesis-generating rather than hypothesis-driven, which also raises concerns about replication and lack of validation [11]. Furthermore, results from GWAS may produce findings that indicate increased risk but cannot determine if or when the disease will manifest, as there are low penetrance gene variants [2]. As a consequence, controversy still exists over whether or not it is ethically sound to return genetic research results to individual participants $[7,11,12]$.

The Veterans Health Administration (VHA) has launched a new genomic program to examine how veterans' genetic information could be used to improve their health care (http://www.research.va.gov/programs/pride/ conferences/docs/accountability/Genomic-Medicine-Program.ppt). To support research in these areas, the VHA proposes to establish a database of annotated clinical samples from consenting volunteer veteran patients. The database would isolate and analyze DNA from participants' blood samples and link these genomic data to participants' electronic health records for epidemiologic analyses. A wide range of phenotypes relevant to both veteran and general populations could be studied [13]. The development of such a program should be informed by attitudes of veterans towards the use of genomic information for re- search. In one such related study, Kaufman et al. [14] conducted a study of veterans' attitudes toward the VHA genomic program and found wide acceptance regarding the return of individual genomic research results to participants, as 9 out of 10 participants said that they would want to know their research results. However, this study is limited in that the questions were asked in the framework of the planned VHA genomic program, not about a specific genomic study. In addition, there has been no comparison of veteran and nonveteran opinions about how genomic research results should be communicated to participants.

As part of the Family Investigation of Nephropathy and Diabetes (FIND) and Extended FIND (EFIND) studies, we are conducting GWAS to identify genetic variants that may increase individuals' susceptibility to diabetes and diabetic nephropathy (DN) [15-18]. To begin to probe subjects' receptiveness of learning their results of genetic research involving their DNA, we conducted secondary analysis of the FIND and EFIND data. Our objective was to identify the preferences of participants in receiving their research genetic results, should any become available. We also compared preferences reported by veteran and nonveteran participants, as past research has shown that veteran patients who use the VHA healthcare system are disadvantaged in terms of health and economic status as compared to the general population or veterans who do not use the VHA health care system [19].

\section{Methods}

The FIND study is a multi-center study aimed at identifying genetic variants that increase susceptibility to diabetes and DN using sib pair design. The San Antonio center participated in the FIND consortium and further extended the FIND study. EFIND is also aimed at identifying genetic variants related to DN. However, it is a multiplex study extending 50 FIND families and including first, second and third generations. About 1,200 consent forms were obtained from subjects enrolled in the FIND study, while 375 consent forms were obtained from subjects enrolled in the EFIND study (fig. 1). All subjects enrolled into the San Antonio center were Mexican-Americans [16]. Currently, the FIND Consortium is conducting GWAS using the Affymetrix GenomeWide Human SNP Array 6.0 to identify several single-nucleotide polymorphisms (SNP) related to type 2 diabetes and DN in subjects who participated in the FIND and EFIND studies $[15,18]$.

Eligibility for the FIND study was determined by probands who had a family history of diabetes and overt nephropathy or end stage renal disease (ESRD) attributed to type 2 diabetes and at least one full sibling who was diabetic (hemoglobin Alc > 7\% or fasting blood glucose $>120 \mathrm{mg} / \mathrm{dl}$ ) with nephropathy (ACR > 0.03 and normal serum creatinine concentration). Blood and urine samples from all participants were collected at the time of the enrollment and sent to a central laboratory for analysis. Clin- 
Fig. 1. Participants included in the analysis based on their veteran status. FIND = Family Investigation of Nephropathy and Diabetes; EFIND = Extended FIND.

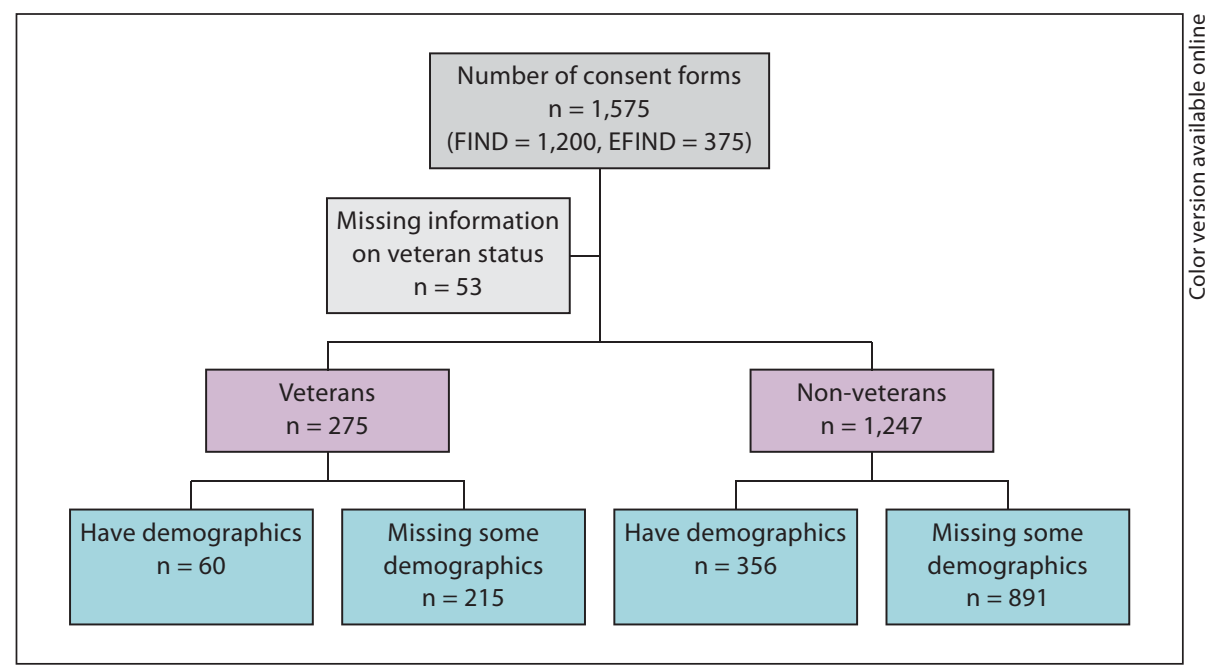

ical diagnoses for diabetes, albuminuria and advanced diabetic nephropathy were established based on information collected from patients' medical records as well as from their laboratory results [15]. A similar approach was implemented for enrolling subjects in the EFIND study. Clinical phenotypes were generated by our local NIH-funded General Clinical Research Center (GCRC). All patients provided written informed consent to participate in the study. The study was approved by the local institutional review board prior to initiation.

The enrollment process for the FIND subjects was conducted by making initial contact with potential probands. All probands were recruited from local clinics, dialysis or transplant units that have high numbers of diabetic nephropathy and/or diabetic participants. Eligible probands were asked to contact their siblings and ascertain their willingness to participate in the study. Willing relatives were then contacted by the study coordinator to complete the enrollment process. The enrollment process for the EFIND subjects was conducted by making initial contact with the FIND subjects and asking them to invite all willing/living relatives. The goal was to extend the FIND family into complex pedigrees (e.g. first, second and third generations). The study coordinator then contacted all willing relatives and enrolled subjects to obtain consent, data and urine and blood samples. Detailed information about the enrollment process is described in a previous publication [16].

For this study, we performed a secondary analysis of the 1,575 consent forms signed by participants enrolled in the FIND and EFIND studies conducted at the San Antonio center in 2000-2004 to investigate their preferences about receiving clinical/lab and/or genetic research results. The consent forms of the FIND and EFIND studies had multiple-choice questions asking about participants' preferences about receiving their: (1) clinical/lab results such as HbAlc values and (2) future genetic results. A trained study coordinator experienced in conducting genetic family study (GFS) obtained informed consent from all participants; the informed consent process lasted for an average of 40 minutes. The study coordinator explained the research study's purposes, procedures, risks, benefits, data and samples ownership, and confidentiality statement as presented in the consent form. The informed consent form had information on how and why lab/clinical measures should be obtained. The consent form stated: 'The blood and urine tests will show us whether (1) you have diabetes, (2) your kidneys function well and (3) your level of cholesterol (fat in the blood) is high or normal. If we find that you have kidney disease, diabetes or other conditions requiring medical attention, we will notify you and/or your doctor, as you may prefer and indicate below.'

In addition, the consent form had information about future genetic findings related to subjects' DNA analysis. As stated in the consent form: 'It might be that, in the future, we will find out more about the genetics of diabetes and kidney disease. This new knowledge might benefit you and/or your relatives and might be used to influence the future health of you or your relatives. However, some people are afraid that it would make it harder to get health or life insurance or to get a job when results from genetic studies are disclosed. You can decide now or later whether you would like to obtain this kind of information.' At the end of the recruitment session, the study coordinator explained the uncertain nature in genetic research findings and emphasized that these findings need to be tested for clinical validity and reliability before implementing into clinical practice. The study coordinator then asked participants to indicate their preferences regarding receiving the results of their blood and urine tests (clinical/lab findings) as well as their genetic future research findings. For example, the question about subjects' preferences concerning clinical/ lab findings were presented in a multiple-choice format and stated: 'Regarding the results of my blood and urine tests inform: (1) me, my address is ..., (2) my doctor, doctor's address is ..., (3) both, (4) do not inform anyone.' A different question with a similar format collected data on subjects' preferences regarding research future genetic results.

The FIND-EFIND databases contained participants' demographic information (e.g. age and gender) and some selected clinical variables, including diabetes and chronic kidney disease. Additionally, in order to compare views from veterans and nonveterans, we identified veteran participants who were VHA patients using the VHA's National Patient Care Database (NPCD). This use of the data was approved by our institutional review board. 
Table 1. Demographics characteristics of subjects who participated in the FIND and EFIND studies

\begin{tabular}{|c|c|c|c|c|}
\hline & Probands & Relatives & Total & $\mathrm{p}$ value \\
\hline Age, mean $\pm S D$ & $56.3 \pm 11.9$ & $45.2 \pm 15.9$ & $51.2 \pm 14$ & $<0.0001$ \\
\hline Participants & $343(22 \%)$ & $1,179(78 \%)$ & $1,522(100 \%)$ & $<0.0001$ \\
\hline \multicolumn{5}{|l|}{ Gender } \\
\hline Male & $173(50.4 \%)$ & $393(33.3 \%)$ & $608(40 \%)$ & \\
\hline Female & $170(49.6 \%)$ & $786(66.6 \%)$ & $914(60 \%)$ & $<0.0001$ \\
\hline \multicolumn{5}{|l|}{ Veterans } \\
\hline Yes & $68(20.0 \%)$ & $207(17.6 \%)$ & $275(18 \%)$ & ns \\
\hline No & $275(80.0 \%)$ & $972(82.4 \%)$ & $1,247(82 \%)$ & \\
\hline
\end{tabular}

\section{Data Analysis}

In this paper, we have included data on the demographic (i.e. age, gender) characteristics for all subjects who participated in the FIND and EFIND studies $(\mathrm{n}=1,575)$. In addition, we have provided data on subjects' preferences regarding receiving their clinical/lab and genetic results. A subset $(n=416)$ from the entire sample was invited to participate in an additional anthropological study to examine ethical issues associated with subjects' participation in GFS. For this subset sample, we have collected additional information on educational level and income. In this paper, we first present results on subjects' demographic characteristics of the entire sample. We then show data on subjects' responses to the clinical/lab and genetic results. Finally, we provide a description of the subset sample of participants including results from logistic regression analysis.

Descriptive statistics, including frequency distribution and means, analyzed continuous and discrete variables. Associations between categorical variables in the form of contingency tables were examined using a $\chi^{2}$ test. Correlations between subjects' responses and selected demographic measures as well as diabetes status were also assessed. To compare age, gender, education, and income between veterans and nonveterans, the variables were reported as means \pm standard deviation (SD) for continuous variables by using a Student's t test and were stated as frequency (percentages) for categorical variables by using a $\chi^{2}$ test. A logistic regression model was performed to find the relationship between the veteran status and participant preferences regarding receiving their genetic research results, controlling for demographics. The findings are presented as percentages in order to demonstrate the trends and variation in responses within our sample and are not intended to imply generalization of the findings to a broader population. The software package SAS Version 9.2 was used for all analyses.

\section{Results}

\section{Subject Selection}

We initially included 1,575 Mexican-American participants who had participated in FIND and EFIND studies and signed the consent form (fig. 1). There were 1,200 consent forms obtained from subjects enrolled in the FIND study, while 375 consent forms were obtained from subjects enrolled in the EFIND study. We excluded 53 total participants whose veteran status data was missing. Of the 1,522 participants remaining, 275 were identified as veterans and 1,247 as nonveterans. For the final analysis comparing veteran and nonveteran status controlling for socio-demographic characteristics, the sample included 416 participants, 60 veterans and 356 nonveterans.

\section{Demographics Characteristics of Subjects}

Participating in the FIND and EFIND Studies

Of the 1,522 participants, 343 (22\%) were probands, while $1,179(78 \%)$ were relatives. The mean age of the probands was $56.3 \pm 11.9$, while the average age of the relatives was $45.2 \pm 15.9$ ( $\mathrm{t}$ test, $\mathrm{p}<0.05)$. Of the probands, 173 (50.4\%) were male and for relatives 393 (33.3\%) were male $\left(\chi^{2}\right.$ test, $\left.\mathrm{p}<0.05\right)$. About $20 \%(68)$ of the probands were veterans, compared to $17 \%$ (207) of the relatives (table 1).

\section{Participants' Preferences regarding Disclosure of \\ Research Results}

Our results indicated a strong desire among participants to receive their lab research results and to be informed about their future research genetic results. The majority of both veteran $(268,97.5 \%)$ and nonveteran $(1,177,94.4 \%)$ participants indicated that they would like to receive their individual clinical lab results ( $\chi^{2}$ test, $\mathrm{p}=$ 0.056). Similarly, in response to the disclosure of future genetic results, 263 veterans (95.7\%) and 1,159 nonveterans (93.1\%) expressed a desire to receive their individual genetic results ( $\chi^{2}$ test; $\left.p=0.0999\right)$. On the other hand, few participants indicated that they would like to share their research results with their physicians; this was true for both veteran and nonveteran participants $(7,2.5 \%$ and $70,5.6 \%$ respectively). Table 2 presents an overview of re- 
Table 2. Responses to disclosure of research results $(n=1,522)$

\begin{tabular}{lccc}
\hline & $\begin{array}{l}\text { Veterans } \\
(\mathrm{n}=275)\end{array}$ & $\begin{array}{l}\text { Nonveterans } \\
(\mathrm{n}=1,247)\end{array}$ & p value \\
\hline $\begin{array}{l}\text { Disclosure of clinical/lab results } \\
\text { Inform me }\end{array}$ & $268(97.5 \%)$ & $1,177(94.4 \%)$ & 0.05 \\
$\quad$ Inform me and my physician & $7(2.5 \%)$ & $70(5.6 \%)$ & 0.099 \\
Disclosure for future genetic results & $263(95.7 \%)$ & $1,159(93.1 \%)$ & $88(6.9 \%)$ \\
$\quad$ Yes & $12(4.3 \%)$ & & \\
No & & \\
\hline
\end{tabular}

sponses given from all of the participants regarding the disclosure of research results. We have conducted several kinds of statistical analysis to assess variations in subjects' preferences and included all 3 groups: Veterans who are patients with diabetes, nonveterans who are patients and nonveterans who are not patients. Our findings did not reveal any significant difference in subjects' responses regarding their preferences on receiving their clinical and future genetic results. We stratified for participants who have a diagnosis of diabetes vs. family members with or without diabetes based on their lab reports. Diabetic diagnosis was considered if individuals' hemoglobin Alc $>7 \%$ or fasting blood glucose $>120 \mathrm{mg} / \mathrm{dl}$. We distinguished between a proband who was a veteran and a sibling who was a nonveteran by identifying their veteran status using the VHA automated Austin National Database. Our analysis showed no difference in subjects' responses if a nonveteran was a family member or not a family member. This maybe due to the fact that all enrolled subjects had a family health history of diabetes.

\section{Regression Analysis for Veterans' Preferences}

For the subset of subjects with demographic data, we assessed their representativeness of the larger study population. The proportion who was veterans was smaller in the demographic subset, $22 \%$ vs $30 \%$ ( $p<0.01$ ). Of the 60 veteran and 356 nonveteran participants who reported sociodemographic information, 5 veterans $(8.3 \%)$ and 63 nonveterans $(17.7 \%)$ were probands, as the majority of both groups were relatives of the probands. The mean age of the 60 veteran participants was $46 \pm 15$, while the average age of the 356 nonveterans was $50 \pm 15$ ( $\mathrm{t}$ test, $\mathrm{p}>0.05$ ). Of the 60 veterans, $29(48.3 \%)$ were male and for the 356 nonveterans, $123(34.6 \%)$ were male ( $\chi^{2}$ test, $\left.\mathrm{p}<0.05\right)$. A majority of both veteran and nonveteran participants, 42 (70\%) and $269(75.6 \%)$ respectively, indicated that they were not formally educated beyond high school ( $\chi^{2}$ test, $\mathrm{p}>0.05)$. Finally, the majority of participants, 41 veterans (83.7\%) and 269 nonveterans (80.3\%), reported an annual household income $<$ USD 20,000 ( $\chi^{2}$ test, $p<0.05$ ) (table 3 ).

This subset did not differ from the overall sample in terms of their responses to the genetic results preference question ( $p>0.05)$. Regression analysis showed no significant relationship $(\mathrm{p}=0.449)$ between the outcome variable (preference to receive genetic research results) and veteran status after controlling for demographics, diabetes status and educational levels (table 4).

\section{Discussion}

In this study, we found that veterans' interest in expressing their preferences about receiving their genetic research results is similar to nonveterans. In addition, a very high proportion, $98 \%$ of veterans and $94 \%$ of nonveteran study participants, indicated that they would like to know their clinical lab research results. This high proportion is similar to findings by Kaufman et al. [14], where a majority of veterans who use the VHA health care system to receive varying degrees of health or psychological care, in a broad range of demographic groups supported the establishment of a genomic database and showed interest in receiving their research results back. Two-thirds of respondents in Kaufman's study said they would be less likely to join the study if they did not receive research results back. Although the desire to learn about one's own health from the study was high, human characteristics were strongly related to whether or not veterans would participate in genetic research.

Current advances in genomics hold a great promise to transform the practice of medicine by 'personalizing' health care $[20,21]$. As a consequence, several large prospective cohort studies are being conducted to examine the influence and interactions of genes, environment and 
Table 3. Socio-demographics characteristics of veterans and nonveterans

\begin{tabular}{|c|c|c|c|}
\hline & $\begin{array}{l}\text { Veterans } \\
(\mathrm{n}=60)\end{array}$ & $\begin{array}{l}\text { Nonveterans } \\
(\mathrm{n}=356)\end{array}$ & $\mathrm{p}$ value \\
\hline Age & $46 \pm 15$ & $50 \pm 15$ & 0.0820 \\
\hline \multicolumn{4}{|l|}{ Gender } \\
\hline Male & $29(48.3)$ & $123(34.6)$ & \\
\hline Female & $31(51.7)$ & $233(65.5)$ & 0.0403 \\
\hline \multicolumn{4}{|l|}{ Education } \\
\hline Below high school & $42(70.0)$ & $269(75.6)$ & \\
\hline Above high school & $18(30.0)$ & $87(24.4)$ & 0.359 \\
\hline \multicolumn{4}{|l|}{ Income (USD)* ${ }^{*}$} \\
\hline$<10,000$ & $21(42.9)$ & $161(48.1)$ & \\
\hline $10,001-19,999$ & $20(40.8)$ & $108(32.2)$ & \\
\hline$\geq 20,000$ & $8(16.3)$ & $66(19.7)$ & 0.722 \\
\hline
\end{tabular}

* 11 veterans and 21 nonveterans did not provide a response regarding their income.

Table 4. Logistic regression for preference to receive genetic research results controlling for demographic factors

\begin{tabular}{lllllll}
\hline & Coefficient $(\beta)$ & SE & Wald $\chi^{2}$ & p value & OR & $95 \%$ CI \\
\hline Intercept & 4.529 & 1.220 & 13.771 & 0.0002 & & \\
Veteran status & 0.400 & 0.528 & 0.572 & 0.449 & 2.224 & $(0.280,17.652)$ \\
Male & 0.0602 & 0.274 & 0.0484 & 0.826 & 1.128 & $(0.386,3.300)$ \\
Above high school & 0.657 & 0.281 & 5.463 & 0.0194 & 0.269 & $(0.089,0.809)$ \\
Age & -0.0284 & 0.0201 & 1.991 & 0.158 & 0.972 & $(0.934,1.011)$ \\
\hline
\end{tabular}

lifestyle on health and disease. Most of these studies use GWAS to identify potential variants that may increase individuals' susceptibility to common chronic diseases such as diabetes $[1,21]$. Communicating genetic research results generated from GWAS remains a major ethical challenge $[7,12,22,23]$. It is evident from our findings that the majority of participants expressed an interest in receiving their genetic research results. Participants' positive response regarding obtaining their genetic research results is expected to grow as genetic research is widely believed to be beneficial by both the general public and individuals diagnosed with certain conditions [14, 24$26]$ and as the increasing growth of direct-to-consumer genetic tests provide arguably more convenient and easily accessible alternatives to obtaining genetic tests [4]. Some studies of public opinion have shown wide support for the return of research results from biobanks $[24,27]$. Other studies have shown participants' desire to receive results about genetic risk assessment for preventable or potentially manageable diseases, as in the case of colorec- tal cancer [28]. In addition, participants have expressed a desire to know their individual results of a genetic test that may reveal their likelihood of developing an untreatable illness, such as Alzheimer's [29]. Throughout these studies, the trend among the majority of participants surveyed has shown that participants optimistically stated their desire to know their individual research results [30]. Whereas these findings and those in our study reveal that participants would like to receive their research results, there should be caution in interpreting and drawing conclusions as this is a complex and controversial issue.

Moreover, the VHA has launched a new genomic program to assess how veterans' genetic information could be used to improve their health care (http://www. research.va.gov/programs/pride/conferences/docs/ accountability/Genomic-Medicine-Program.ppt). This new program will establish a large database of annotated clinical samples from consenting veterans. The database would isolate and analyze DNA from participants' blood samples and link these genomic data to participants' elec- 
tronic health records for epidemiologic analyses. A wide range of phenotypes relevant to both the veteran and general populations could be studied. The creation of a large genomic research database will allow future GWAS to identify genetic variants associated with common chronic diseases among veterans [13].

Proponents of returning research results to participants may defer to the principle of respect for persons, maintaining that the choices made by individuals who are capable of making decisions for themselves should be treated with the highest regard. Those in support of returning results focus on participants' desire, stressing that respect for persons does not imply mandating participants to accept their individual results, but rather the minimum of offering the choice to receive results $[6,9]$. Disclosing research results may allow the participants to take preventative or precautionary measures to improve their quality of life [31]. It could also potentially benefit researchers as it may enhance participants' retention and trust in the research process $[8,10]$. Some have argued that researchers should inform participants of any research results 'regarding genetic risk when significant implications to their health are confirmed in the course of research' [32]. However, it is equally important to consider the scope and limitations of such genetic research findings and the negative implications of returning preliminary genetic research results for individuals [21]. Some participants may take radical measures after receiving their results due to anxiety-ridden fear, and others may experience distress if they are told they are susceptible to an illness that does not currently have any treatment options. Further complications of returning individual research results involve the lack of time and trained personnel required to deliver the results $[10,22$, 33]. Additionally, with the proliferation of direct-to-consumer (DTC) genetic testing available, there are additional ethical considerations to take into account. A primary concern of DTC genetic testing is that they may be ordered directly by individuals, and therefore there is often little or no physician involvement $[4,34,35]$. This presents a concern regarding the communication of genetic test results as it is conducted outside of a clinical setting and are often interpreted by individuals themselves. As a result, this opens up the potential for misreporting, misinterpreting and misapplication of results [35]. Furthermore, DTC tests are often not clinically evaluated, thereby the value and/or risks of such tests remain unclear [36].

Given the implications of this issue, it is essential that both participants and researchers involved in genetic studies be fully aware of the ethical issues associated with such research. With the expansion of genomic research, it is apparent that there is a need for a policy to determine whether researchers should return individual results of genetic research. Many have proposed solutions on how and under what conditions researchers should disclose individual genetic results. The National Bioethics Advisory Commission (NBAC) and The National Heart, Lung, and Blood Institute (NHLBI) have advised against informing participants of their results until certain criteria have been met [10,33]. However, others hold the belief that all individual results should be offered to research participants [6]. Finally, in determining whether participants should receive results or not, Ravitsky and Wilfond [23] have set forth the recommendation that each situation should be assessed on a case-by-case basis [37]. Despite varied views on how and what results should be returned to participants, there is a general consensus that a standardized set of disclosure guidelines would be valuable and, at times, necessary in order to provide a welldefined and structured plan particularly to address issues, such as study limitations and data interpretation $[38,39]$. Similarly in regards DTC genetic testing, in order to prevent undue physical and emotional risks to the individuals, it will prove to be indispensable to educate the public about the value and limitations of these tests and establish regulations as well [36].

\section{Implications}

Our findings have several implications. While the majority of participants revealed that they would like to receive their research results, only a small portion of participants indicated that they would like to share their results with their physicians. This suggests there is a need for informing and counseling participants as well as educating primary medical providers about the meaning of genetic research results. Informing participants of potential plan options regarding the disclosure of genetic research results may be conducted during the consent process. Consent forms should explicitly articulate the plan of communicating all possible research findings, including aggregate findings, specific results that have probable implications for the participant and preliminary individual results that may have less significance. Many institutions, including ours, have already implemented these principles in their informed consent documents. This will allow participants to decide whether to participate or decline from the study in a truly informed manner.

In addition, our findings showed no difference between veteran and nonveteran participants regarding their preferences in receiving genetic research results. As 
discussion and genetic research progress at the VHA, we suggest that investigators work closely with their Institutional Review Board and VHA staff to design a comprehensive approach to communicating aggregate and individual results and to address disclosure in informed consent documents. The application of such programs and the relevance of the ethical dilemma of returning individual genetic results will become even more pertinent in the near future as scientists expect the results gathered from GWAS to identify people who are at risk for common chronic diseases.

\section{Future Studies}

The indeterminate nature of communicating genetic research results suggests the need for continued empirical work to address unresolved and other unexplored issues. Future studies should be conducted to further assess the duty to disclose results. Whether researchers should return individual genetic results to subjects who request them raises the issue of whose responsibility it should be to disclose such results, when the results should be disclosed, how the results should be disclosed with participants, and to whom the results should be disclosed. This concern extends not only to the research participants but also to family members who may not wish to be involved in the research and to ethnic groups whose characterization may involve genetic findings. Additionally, future studies should focus on how the practice of communicating results to participants affects their views of research. Although hypothesized, it remains unclear whether it will significantly affect participants' perceptions of investigators and the field of biomedical research or influence their likelihood of enrolling in future studies. Finally, the risks and benefits of disclosing results must be assessed for the researchers, providers and health care practices, taking into consideration the necessary support systems and financial costs associated with providing results. Not only will these issues help to establish a better understanding for the future of genetic research, it

views of this particular minority group. It is important to study minority populations in order to bring attention to any issues specific to that group and to gain a better understanding about their concerns; especially as such groups may be more vulnerable than the general public. In addition, the study design did not allow us to explore why participants prefer to receive results, how they interpreted the offer to return 'genetic results' and whether or not they would be satisfied with the return of aggregate results. However, we have conducted several qualitative analyses on a smaller sample to examine factors affecting participants' preferences to receiving their results. Our findings showed that participants were interested in receiving their genetic results and they underestimated the potential risks associated with their participation in genetic family studies [40]. However, these data were collected in 2000-2004, and as there have been many advances in genetics since then, there may be changes in public perceptions that our findings do not address. Additionally, due to such concerns regarding ethical and social implications of communicating genetic research results, several states have enacted laws protecting individuals from discrimination by employers and health insurers. Furthermore, with the U.S. Congress' recent passing of the Genetic Information Nondiscrimination Act (GINA), which provides national protection of genetic information, views of both veterans and the general public may have changed [41].

\section{Acknowledgements}

We wish to thank all participants of the FIND and EFIND Studies for their cooperation and generous participation. This study was supported by funds from NIH/NIDDK (P50 DK061597). This work was also supported by the VHA-HSR\&D (PPO 09-241 and DNA 08-129: Nedal Arar PhD). The views expressed in this article are those of the authors and do not necessarily represent the views of the Department of Veterans Affairs. will also help to enhance communication between researchers and participants regarding research data.

\section{Limitations}

Our study had a few limitations. As our analysis was limited to responses from participants of Mexican-American background enrolled at the San Antonio FIND Study Center, further research including participants from multi-ethnic groups is justified. Although our current findings cannot be generalized to the general population, our study's focus on Mexican-Americans highlights the

References $\checkmark 1$ Wellcome Trust Case Control Consortium: Genome-wide association study of 14,000 cases of seven common diseases and 3,000 shared controls. Nature 2007;447:661-678.

-2 Rief W, Conradt M, Dierk JM, Rauh E, Schlumberger P, Hinney A, Hebebrand J: Is information on genetic determinants of obesity helpful or harmful for obese people? - A randomized clinical trial. J Gen Intern Med 2007;22:1553-1559.

- 3 Vos J, Otten W, van Asperen C, Jansen A, Menko F, Tibben A: The counsellees' view of an unclassified variant in BRCA1/2: recall, interpretation, and impact on life. Psychooncology 2008;17:822-830.
Arar/Seo/Lee/Abboud/Copeland/Noel/ Parchman 
$\checkmark 4$ Haga SB: Ethical issues of predictive genetic testing for diabetes. J Diabetes Sci Technol 2009;3:781-788.

5 National Commission for the Protection of Human Subjects of Biomedical and Behavioral Research. The Belmont Report: Ethical Principles and Guidelines for the Protection of Human Subjects of Research. April 1979.

-6 Fernandez CV, Kodish E, Weijer C: Informing study participants of research results: an ethical imperative. IRB 2003;25:12-19.

7 Miller FA, Christensen R, Giacomini M, Robert JS: Duty to disclose what? Querying the putative obligation to return research results to participants. J Med Ethics 2008;34: 210-213.

8 Shalowitz DI, Miller FG: Disclosing individual results of clinical research: implications of respect for participants. JAMA 2005;294: 737-740.

-9 Shalowitz DI, Miller FG: The search for clarity in communicating research results to study participants. J Med Ethics 2008;34:e17.

10 Bookman EB, Langehorne AA, Eckfeldt JH, Glass KC, Jarvik GP, Klag M, Koski G, Motulsky A, Wilfond B, Manolio TA, Fabsitz RR, Luepker RV; NHLBI Working Group: Reporting genetic results in research studies: summary and recommendations of an NHLBI working group. Am J Med Genet A 2006; 140:1033-1040.

- 11 Renegar G, Webster CJ, Stuerzebecher S, Harty L, Ide SE, Balkite B, Rogalski-Salter TA, Cohen N, Spear BB, Barnes DM, Brazell $\mathrm{C}$ : Returning genetic research results to individuals: points-to-consider. Bioethics 2006; 20:24-36.

12 Affleck P: Is it ethical to deny genetic research participants individualised results? J Med Ethics 2009;35:209-213.

13 Przygodzki RM: Genomic Medicine Program: an overview. http://www.research. va.gov/programs/pride/conferences/docs/ accountability/Genomic-Med-Program.ppt (accessed February 18, 2010).

-14 Kaufman D, Murphy J, Erby L, Hudson K, Scott J: Veterans' attitudes regarding a database for genomic research. Genet Med 2009; 11:329-337.

- 15 Knowler WC, Coresh J, Elston RC, Freedman BI, Iyengar SK, Kimmel PL, Olson JM, Plaetke R, Sedor JR, Seldin MF; Family Investigation of Nephropathy and Diabetes Research Group: The Family Investigation of Nephropathy and Diabetes (FIND): design and methods. J Diabetes Complications 2005; 19:1-9.

-16 Arar NH, Hazuda HP, Plaetke R, Sartorio V, Arar MY, Abboud HE: Familial clustering of diabetic nephropathy: perceptions and risk recognition among Mexican-American patients with a family history of diabetes. Diabetes Spectr 2003;16:136-142.
17 Schelling JR, Abboud HE, Nicholas SB, Pahl MV, Sedor JR, Adler SG, Arar NH, Bowden DW, Elston RC, Freedman BI, Goddard KA, Guo X, Hanson RL, Ipp E, Iyengar SK, Jun G, Kao WH, Kasinath BS, Kimmel PL, Klag MJ, Knowler WC, Nelson RG, Parekh RS, Quade SR, Rich SS, Saad MF, Scavini M, Smith MW, Taylor K, Winkler CA, Zager PG, Shah VO, Family Investigation of Nephropathy and Diabetes Research Group: Genome-wide scan for estimated glomerular filtration rate in multi-ethnic diabetic populations: the Family Investigation of Nephropathy and Diabetes (FIND). Diabetes 2008;57:235-243.

18 Affymetrix I. http://investor.affymetrix $\mathrm{com} /$ phoenix.zhtml?c=116408\&p=irolnewsArticle\&ID $=1004567$ \&highlight $=(\mathrm{ac}-$ cessed February 18, 2010).

19 Morgan RO, Teal CR, Reddy SG, Ford ME, Ashton CM: Measurement in Veterans Affairs Health Services Research: veterans as a special population. Health Serv Res 2005;40: 1573-1583.

20 Ginsburg GS, McCarthy JJ: Personalized medicine: revolutionizing drug discovery and patient care. Trends Biotechnol 2001;19: 491-496.

21 McGuire AL, Cho MK, McGuire SE, Caulfield T: Medicine. The future of personal genomics. Science 2007;317:1687.

22 McGuire AL, Caulfield T, Cho MK: Research ethics and the challenge of whole-genome sequencing. Nat Rev Genet 2008;9:152-156.

23 Ravitsky V, Wilfond BS: Disclosing individual genetic results to research participants. Am J Bioeth 2006;6:8-17.

24 Godard B, Marshall J, Laberge C: Community engagement in genetic research: results of the first public consultation for the Quebec CARTaGENE project. Community Genet 2007;10:147-158.

25 Fernandez CV, Santor D, Weijer C, Strahlendorf C, Moghrabi A, Pentz R, Gao J, Kodish $\mathrm{E}$ : The return of research results to participants: pilot questionnaire of adolescents and parents of children with cancer. Pediatr Blood Cancer 2007;48:441-446.

26 Hoeyer K, Olofsson BO, Mjorndal T, Lynoe $\mathrm{N}$ : Informed consent and biobanks: a population-based study of attitudes towards tissue donation for genetic research. Scand Public Health 2004;32:224-229.

27 Murphy J, Scott J, Kaufman D, Geller G, LeRoy L, Hudson K: Public expectations for return of results from large-cohort genetic research. Am J Bioeth 2008;8:36-43.

28 Ceballos RM, Newcomb PA, Beasley JM, Peterson S, Templeton A, Hunt JR: Colorectal cancer cases and relatives of cases indicate similar willingness to receive and disclose genetic information. Genet Test 2008; 12 : $415-420$.
29 Wendler D, Pentz R: How does the collection of genetic test results affect research participants? Am J Med Genet A 2007;143A:17331738 .

30 Fernandez CV, Gao J, Strahlendorf C, Moghrabi A, Pentz RD, Barfield RC, Baker JN, Santor D, Weijer C, Kodish E: Providing research results to participants: attitudes and needs of adolescents and parents of children with cancer. J Clin Oncol 2009;27:878883.

31 Richards MP, Ponder M, Pharoah P, Everest S, Mackay J: Issues of consent and feedback in a genetic epidemiological study of women with breast cancer. J Med Ethics 2003;29:9396.

32 Matsui K, Lie RK, Kita Y, Ueshima H: Ethics of future disclosure of individual risk information in a genetic cohort study: a survey of donor preferences. J Epidemiol 2008;18:217224

33 Fernandez CV, Skedgel C, Weijer C: Considerations and costs of disclosing study findings to research participants. CMAJ 2004; 170:1417-1419.

34 Caulfield T, Ries NM, Ray PN, Shuman C, Wilson B: Direct-to-consumer genetic testing: good, bad, or benign? Clin Genet 2010; 77:101-105

- 35 Marietta C, McGuire AL: Direct-to-consumer genetic testing: is it the practice of medicine? J Law Med Ethics 2009;37:369374 .

36 Schickedanz AD, Herdman RC: Direct-toconsumer genetic testing: the need to get retail genomics right. Clin Pharmacol Ther 2009;86:17-20.

37 Moutel G, Duchange N, Raffi F, Sharara LI, Theodorou I, Noel V, de Montgolfier S, Callies I, Bricaire F, Hervé C, Leport C; APROCO-COPILOTE Study Group: Communication of pharmacogenetic research results to HIV-infected treated patients: standpoints of professionals and patients. Eur J Hum Genet 2005;13:1055-1062.

38 Kristman VL, Kreiger N: Information disclosure in population-based research involving genetics: a framework for the practice of ethics in epidemiology. Ann Epidemiol 2008:18:335-341.

39 Dressler LG: Disclosure of research results from cancer genomic studies: state of the science. Clin Cancer Res 2009;15:4270-4276.

-40 Arar NH, Hazuda H, Steinbach R, Arar MY, Abboud HE: Ethical issues associated with conducting genetic family studies of complex disease. Ann Epidemiol 2005;15:712719 .

41 Ginsburg GS: Genomic medicine: 'grand challenges' in the translation of genomics to human health. Eur J Hum Genet 2008; 16: 873-874. 